\title{
Prevalence and Characterization of Plasmid-mediated Quinolone Resistance Genes among Escherichia coli Strains Isolated from Different Water Sources in Alborz Province, Iran
}

\author{
Reza Ranjbar ${ }^{1}$, Shahrzad Tavanania ${ }^{2}$, Azar Sabokbar ${ }^{2}$, Faham Khamesipour ${ }^{3,4, *}$ \\ ${ }^{1}$ Molecular Biology Research Center, Systems Biology and Poisonings Institute, Baqiyatallah University of Medical Sciences, Tehran, Iran \\ ${ }^{2}$ Department of Microbiology, Faculty of Science, Islamic Azad University, Karaj Branch, Karaj, Iran \\ ${ }^{3}$ Cellular and Molecular Research Center, Sabzevar University of Medical Sciences, Sabzevar, Iran \\ ${ }^{4}$ Health Policy Research Center, Institute of Health, Shiraz University of Medical Science, Shiraz, Iran \\ *Corresponding author. E-mail: f.khamesipour@iaushk.ac.ir; faham.khamesipour@yahoo.com \\ Received date: Jun 27, 2018; Revised date: Aug 31, 2018; Accepted date: Sep 14, 2018
}

\section{Abstract}

B

ACKGROUND: This study was conducted to investigate the prevalence of quinolone resistance associated (qnr) antibiotic resistance among Escherichia coli strains isolated from different water sources in Alborz province, Iran.

METHODS: E. coli strains were isolated and identified by standard microbiological and biochemical tests from surface water sources in Alborz province, Iran in 2013. Fluoroquinolone-resistant isolates were determined using the antimicrobial susceptibility test determined by the Kirby-Bauer assay. Total genomic and plasmid DNA were extracted by boiling method. The presence of $g n r$ genes in all nalidixic-acid and ciprofloxacin-resistant $E$. coli strains was determined by Polymerase Chain Reaction (PCR). The PCR amplicons were visualized after electrophoresis stained with ethidium bromide.

RESULTS: One hundred E. coli strains were isolated from the water sources examined in this study. As much as
$22.7 \%$ and $7.3 \%$ of the isolates were resistant to nalidixic acid and ciprofloxacin respectively. While $q n r S$, $q n r B$ and $q n r A$ genes were detected in $28 \%, 9 \%$ and $1 \%$ of fluoroquinolone-resistant isolates respectively. All fluoroquinolone-susceptible isolates however did not contain any of the qnr genes.

CONCLUSION: This study reflects an increasing prevalence of fluoroquinolone-resistant E. coli strains in surface water sources. Underlining the importance of surface water sources as reservoirs for dissemination of potentially pathogenic $E$. coli and horizontal gene transfer between other waterborne bacterial species. Other possible mechanisms of resistance should also be investigated for better characterization of quinolone-resistant $E$. coli isolates. Therefore, immediate measures are needed to control and treat water sources more effectively.

KEYWORDS: antibiotic resistance, E. coli, qnr genes, water sources

Indones Biomed J. 2019; 11(1): 36-41

\section{Introduction}

Escherichia coli (E. coli) is important enteric bacteria which exist as a commensal and could become pathogenic to humans and various animal species.(1-5) It is responsible for significant socio-economic and health concerns in various countries worldwide.(6-8) The abuse of antimicrobials during animal husbandry, human and animal chemotherapy has over time encouraged the development and dissemination of antibiotic resistance genes by microorganisms.(9) This increasing antimicrobial resistance by microorganisms, 
suggested to be mediated by antimicrobial resistance determinants which are carried by genetic components such as plasmids, transposons and integrons $(9,10)$, conotes fatal consequences for human and animal health worldwide.

Several studies have recently determined that plasmids play a vital role in the propagation of antibiotic resistance genes from pathogenic strains to generic strains of various microbes including E. coli.(1-5) Presently, it is more difficult to therapeutically manage infections due to the high incidence and prevalence of antibiotic resistance which is mainly due to the abundance of transmissible multiple drug resistance plasmids among Gram-negative bacteria such as the enterobacteriaceae.(6-8) For example, the treatment of $E$. coli infections has been complicated by the emergence and dissemination of plasmid-mediated resistance to fluoroquinolones.(11-21)

The emergence of plasmid-mediated quinolone resistance (PMQR), first discovered in a multi-drug resistant urinary Klebsiella pneumoniae isolate in 1998, has been associated with the Plasmid-Mediated QuinoloneResistance ( $q n r)$ gene. Genetic studies have identified five qnr genes namely qnr $A, q n r B, q n r S$, qnrC and $q n r D .(5,9-11)$ Two additional mechanisms of PMQR have been described, including the drug modification by the acetyl transferase $\mathrm{AAC}\left(6^{\prime}\right)-\mathrm{Ib}-\mathrm{cr}$ and active efflux by QepA and OqxAB, which are pumps related to major facilitator superfamily transporters. $(14,22)$

There is currently insufficient data on the prevalence of $q n r$ genes among $E$. coli isolates recovered from water sources in Iran. This study was therefore conducted to investigate the presence of plasmid-mediated qnrA, qnrS and $q n r B$ genes among the quinolone-resistant $E$. coli isolated from different water sources in Alborz province, Iran.

\section{Methods}

\section{Bacterial Isolates and Antimicrobial Susceptibility Testing}

Between October, 2011 and October, 2012, water samples were collected from surface water sources in Alborz province, Iran. One-hundred E. coli strains were identified using standard methods (APHA/AWWA/WEF 2012) and previously described biochemical tests.(23) All isolates were screened for quinolone and fluoroquinolone resistance using the disk diffusion method described by Kirby-Bauer test. The following antibiotics were tested: nalidixic acid (30 $\mu \mathrm{g} /$ disk), norfloxacin $(10 \mu \mathrm{g} / \mathrm{disk})$, ciprofloxacin (5 $\mu \mathrm{g} /$ disk), rifampin (30 $\mu \mathrm{g} /$ disk), tetracycline (30 $\mathrm{u} /$ disk), tobramycin (25 $\mu \mathrm{g} /$ disk), nitrofuranton $(10 \mu \mathrm{g} /$ disk $)$, chloramphenicol (30 $\mu \mathrm{g} / \mathrm{disk})$, amikacin (30 u/disk) and gentamicin (30 $\mu \mathrm{g} / \mathrm{disk})$. Results were read as susceptible or resistant according to the criteria recommended via the CLSI and the manufacturer's protocol (Mast Group, Bootle, UK).

\section{DNA Extraction and Primer Design}

Total genomic DNA of $E$. coli isolates found to be resistant to at least one antibiotic in the disk diffusion method were extracted using a DNA extraction kit (AccuPrep ${ }^{\circledR}$ Genomic DNA Extraction Kit, Bioneer, Daejeon, South Korea).

The desired gene sequence was extracted from the National Center for Biotechnology Information (NCBI) database and then a pair of specific primers was designed for each gene by using the online application, Primer3 (http://frodo.wi.mit.edu/primer3). The specificities of the primers were evaluated using Primer-blast by Uniform Resource Locator (URL) (http://www.ncbi.nih.gov/tools/ primer-blast).

\section{qnr Gene Amplification by Polymerase Chain Reaction (PCR)}

The $q n r S, q n r A$ and $q n r B$ genes were amplified in quinolone and fluoroquinolone- resistant $E$. coli strains using the following primers: Forward: 5'-ACG ACA TTC GTC AAC TGC AA-3' and Reverse: 5'-TTA ATT GGC ACC CTG TAG GC $-3^{\prime}$ to amplify the 417 bp fragment of the $q n r S$ gene; Forward: 5'-ATTTCTCACGCCAGGATTTG-3' and Reverse: 5'- GATCGGCAAAGGTTAGGTCA-3' to amplify the 516 bp fragment of the qnrA gene and Forward: 5'-GTT GGC GAAAAA ATT GAC AGAA-3' and Reverse: 5'-ACT CCG AAT TGG TCA GAT CG-3' to amplify the 469 bp fragment of the $q n r B$ gene. $(24,25)$

The amplification conditions included an initial denaturation step of $95^{\circ} \mathrm{C}$ for 5 minutes, 30 cycles consisting of $94^{\circ} \mathrm{C}$ for 1 minute, $52.2^{\circ} \mathrm{C}, 53.4^{\circ} \mathrm{C} 51.2^{\circ} \mathrm{C}$ for 1 minute for $q n r S, q n r B$ and $q n r A$ genes, respectively and $72^{\circ} \mathrm{C}$ for 1 minute, and $72^{\circ} \mathrm{C}$ for 7 minutes in the final extension. The E. coli ATCC 25922 obtained from the Institute of Hygiene, University of Palermo in Italy were used as a positive control and strains which lack the qnr genes in Molecular Biology Research Center, University of Medical Sciences, Tehran were selected as negative control. The electrophoresis of PCR products was performed on $1.5 \%$ agarose gel, and then the gels were stained in ethidium bromide for 15 minutes and visualized in a gel document system (BioRad XR+, Hemel Hempsted, UK). 


\section{Results}

All $100 \mathrm{E}$. coli isolates tested showed resistance to all the antibiotics used with the greatest resistance being recorded to rifampin $(93.6 \%)$, followed by gentamicin $(27.1 \%)$ while the least resistance was to nitrofuranton (1.0\%) (Figure 1).

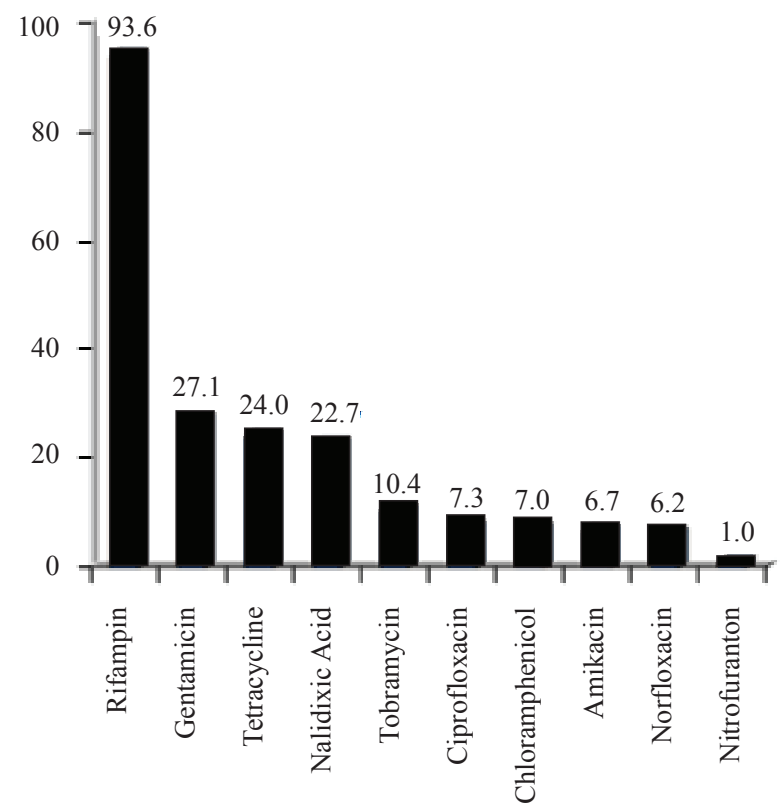

Figure 1. The rate and percent of resistance $E$. coli isolates to antibiotics was shown.

Furthermore, $22.7 \%, \quad 7.3 \%$ and $6.2 \%$ of the isolates were resistant to Nalidixic acid, Ciprofloxacin and Norfloxacin respectively. The highest intermediate phenotypes were recorded against nalidixic acid (8.24\%) while the lowest intermediate phenotypes were recorded against ciprofloxacin (4.16\%). 17\% of E. coli isolates were resistant to at least one of the tested quinolone antibiotics, and $6 \%$ were susceptible to nalidixic acid, ciprofloxacin and norfloxacin, simultaneously (Table 1).

Table 1. Quinolone and fluoroquinolone-resistant isolates by disk diffusion method

\begin{tabular}{lccc}
\hline Antibiotic & \multicolumn{3}{c}{ Isolates, n (\%) } \\
& Resistant & Intermediate & Sensitive \\
\hline Nalidixic acid & 22.7 & 8.1 & 69.2 \\
Ciprofloxacin & 7.3 & 4.5 & 88.2 \\
Norfloxacin & 6.2 & 6.3 & 87.5 \\
\hline
\end{tabular}

Of the 22 quinolone-resistant isolates, $95.4 \%, 40.9 \%$ and $4.5 \%$ were positive for $q n r S$, qnrB and $q n r A$ genes respectively (Figures 2, 3 and 4). The prevalence of qnr genes among eight quinolone-intermediate isolates were $87.5 \%$ for $q n r S, 0 \%$ for $q n r B$ and $q n r A$. Of the 30 quinolone-resistant and intermediate isolates, $26.6 \%$ had the $q n r S$ and $q n r B$ genes, $3.3 \%$ had the $q n r S$ and $q n r A$ genes while $0 \%$ had the $q n r A$ and $q n r B$ genes simultaneously.

\section{Discussion}

Food and water-borne infections constitute public health concerns especially in under-developed and developing countries, and E. coli plays an important pathogen involved gastrointestinal and urinary tract diseases.(26,27) Multidrug resistance of $E$. coli strains recorded in this study is in tandem with the reports of various studies.(26-30) This may be suggestive of high rate of contamination of various water sources with human and animal wastes with antibiotic resistant E. coli strains in the Alborz province, Iran. Furthermore, these antibiotic resistant $E$. coli strains in the aquatic environment may predispose to the spread of the antibiotic resistance among other closely related organisms usually by the exchange of genetic information. $(26,27)$ The relatively high level of resistance to quinolones recorded in the present study could be attributed to misuse or abuse of these antibiotics.

The $22.7 \%, 7.3 \%$ and $6.2 \%$ resistance rates to nalidixic acid, ciprofloxacin and norfloxacin respectively recorded among water-borne $E$. coli strains in this study corroborates various reports indicating the increase in fluoroquinolone resistance in $E$. coli isolates of different origins.(24,28-

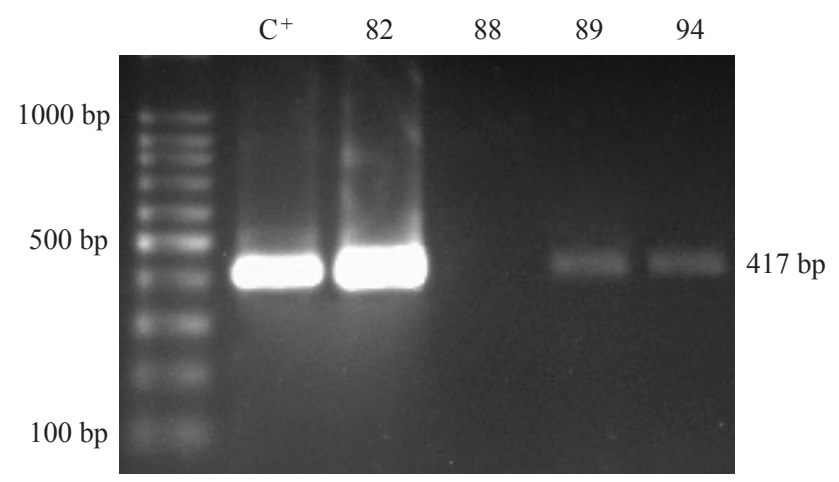

Figure 2. PCR amplification of $q n r S$ gene in resistant $E$. coli isolates. Electrophoresis of PCR product on $1.5 \%$ agarose gel. First lanes, Marker $100 \mathrm{bp}$; lane $2(\mathrm{C}+)$, E. coli qnrS-positive control; lane 4 (No.88), E. coli qnrS-negative isolate; lanes 3 (No.82), 5 (No.89) and 6 (No.94), E. coli qnrS-positive isolates. 


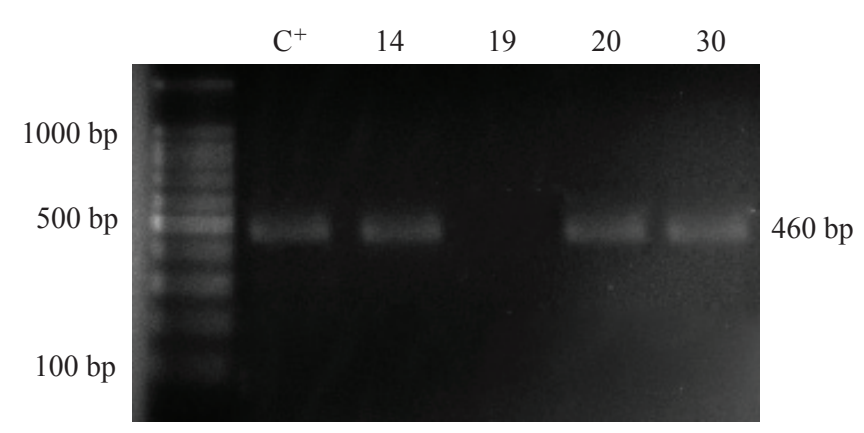

Figure 3. PCR amplification of $q n r B$ gene in resistant $E$. coli isolates. Electrophoresis of PCR product on $1.5 \%$ agarose gel. First lanes, Marker 100 bp; lanes 3 (No.14), 5 (No.20) and 6 (No.30), $E$. coli qnrB-positive isolates; lanes 4 (No.19), E. coli qnrB-negative isolate; lane $2(\mathrm{C}+)$, E. coli qnrB-positive control.

31) Similarly, high resistance rates to fluoroquinolones were reported by various studies on water worldwide.(3234) The most culpable reason for the resistance patterns of E. coli observed in this study is the indiscriminate use of antibiotics for medical and veterinary management of infections which has been reported to predispose to the development of resistance.(30)

However, the discrepancies in the patterns seen in different reports may be associated to the differences in animal husbandry practices and environmental conditions. Several study from India, Canada and Bangladesh, reported the presence of antibiotic resistant E. coli in water.(35-37) A higher frequency of resistance against $\beta$-lactam, quinolone and floroquinolone antibiotics was observed among the isolates from household water in study by Talukdar, et al.(37)

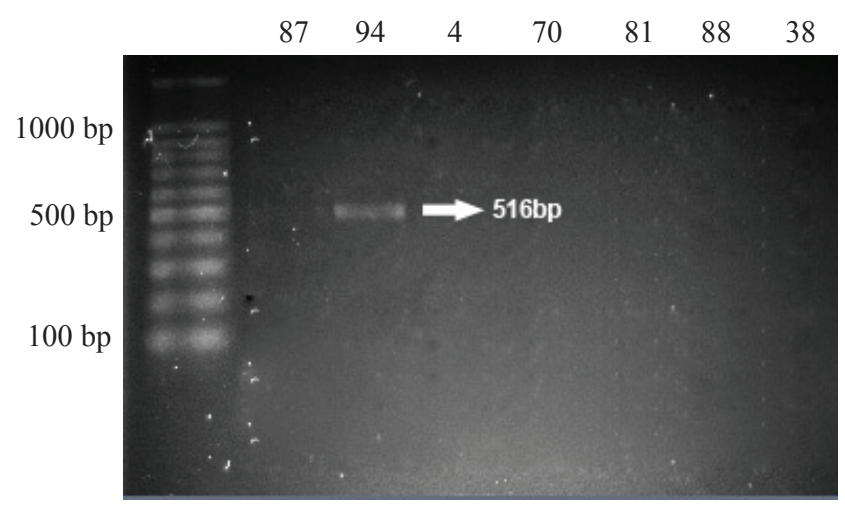

Figure 4. PCR amplification of $q n r A$ gene in resistant $E$. coli isolates. Electrophoresis of PCR product on $1.5 \%$ agarose gel. First lanes, Marker 100 bp; lane 2 (No.87) and lane 4-8 (No.4, 70, 81, 88, 38), E. coli qnrA-negative isolates; lanes 3 (No.94), E. coli $q n r A$ - positive isolate.
A $q n r S$ gene was identified in a water-borne bacterial species, isolated from the River Seine in Paris and Swiss lake.(37) The prevalence of $28 \%, 9 \%$ and $1 \%$ of $q n r S$, $q n r B$ and qnrA genes respectively in the quinolone-resistant $E$. coli isolates in the present study was higher than the report in India, where the rate of qnr genes among resistant isolates of E. coli was $0.85 \% .39$ Quinolone resistance was also recorded in some $q n r S, q n r A$ and $q n r B$-negative isolates in this study which signifies that other qnr genes or resistance mechanisms, such as mutations in the target enzyme (e.g., DNA gyrase and topoisomerase IV) and/or activation of efflux pumps, may be involved.42 Point mutations related to fluoroquinolone resistance were observed at $\mathrm{S} 83$ to $\mathrm{L}$ and D87 to N or Y in the GyrA subunit and S80 to R or I and E84 to $\mathrm{G}$ in the ParC subunit.(38-42)

\section{Conclusion}

In conclusion, to the best of our knowledge, this is the first report of the presence of fluoroquinolone-resistance genes in E. coli isolated from surface waters in Iran. The results of this study revealed a higher resistance to nalidixic acid than other fluoroquinolones with a predominance of qnrS gene among the quinolone-resistant $E$. coli isolates while the occurrence of the qnrA gene was lowest. The presence of these genes in these $E$. coli strains portends the risk of transfer of genetic information via plasmids to other bacteria there by increasing the antibiotic resistance reported in these bacteria.

These findings emphasize the importance of prescribed use of these antibiotics which will help to limit the potential spread of resistant genes. Proper regulation is needed to ensure that the correct dosages of these drugs are administered when they are indicated as the drug of choice in an infection. To gain more insight into the molecular characterization of quinolone-resistant $E$. coli isolates, other possible mechanisms of resistance, changes in expression of efflux pumps, or even novel mechanisms should also be investigated. Therefore, immediate measures are needed to control and treat water sources more effectively.

\section{Acknowledgement}

We would like to thank the Clinical Research Development Center of Baqiyatallah Hospital for their kindly cooperation. This study was financially supported in part by Clinical Research Development Center of Baqiyatallah Hospital. 


\section{References}

1. Accogli M, Fortini D, Giufre M, Graziani C, Dolejska M, Carattoli $\mathrm{A}$, et al. IncI1 plasmids associated with the spread of CMY-2, CTX-M-1 and SHV-12 in Escherichia coli of animal and human origin. Clin Microbiol Infect. 2013; 19: E238-40.

2. Amiri HS, Ranjbar R, Sohrabi N, Khamesipour F. Molecular typing of uropathogenic Escherichia coli strains isolated from patients by REP-PCR. Sovremennye Tehnologii V Medicine. 2017; 9: 71-5.

3. Torkan S, Bahadoranian MA, Khamesipour F, Anyanwu MU. Detection of virulence and antimicrobial resistance genes in Escherichia coli isolates from diarrhoiec dogs in Iran. Arch Med Vet. 2016; 48: 181-90.

4. Tajbakhsh E, Ahmadi P, Abedpour-Dehkordi E, Arbab-Soleimani N, Khamesipour F. Biofilm formation, antimicrobial susceptibility, serogroups and virulence genes of uropathogenic E. coli isolated from clinical samples in Iran. Antimicrob Resist Infect Control. 2016; 5: 11. doi:10.1186/s13756-016-0109-4.

5. Ranjbar R, Hosseini S, Zahraei-Salehi T, Kheiri R, Khamesipour F. Investigation on prevalence of Escherichia coli strains carrying virulence genes ipaH, estA, eaeA and bfpA isolated from different water sources. Asian Pac J Trop Dis. 2016; 6: 278-83.

6. Molton JS, Tambyah PA, Ang BS, Ling ML, Fisher DA. The global spread of healthcare-associated multidrug-resistant bacteria: a perspective from Asia. Clin Infect Dis. 2013; 56: 1310-8.

7. Tajbakhsh E, Khamesipour F, Ranjbar R, Ugwu IC. Prevalence of class 1 and class 2 integrons in multi-drug resistant Escherichia coli isolated from aquaculture water in Chaharmahal Va Bakhtiari province, Iran. Ann Clin Microbiol Antimicrob. 2015; 14: 37. doi: 10.1186/s12941-015-0096-y.

8. Rahimi E, Shirazi F, Khamesipour F. Isolation and study of the antibiotic resistance properties of Shigella species in meat and meat products. J Food Process Preserv. 2017; 41: e12947. doi: 10.1111/ jfpp. 12947.

9. Strahilevitz J, Jacoby GA, Hooper DC, Robicsek A. Plasmid-mediated quinolone resistance: a multifaceted threat. Clin Microbiol Rev. 2009; 22: 664-89.

10. Abdi S, Ranjbar R, Vala MH, Jonaidi N, Bejestany OB, Bejestany FB. Frequency of bla TEM, bla SHV, bla CTX-M, and qnrA among Escherichia coli isolated from urinary tract infection. Arch Clin Infect Dis. 2014; 9: e18690. doi: 10.5812/archcid.18690.

11. Khamesipour F, Tajbakhsh E. Analyzed the genotypic and phenotypic antibiotic resistance patterns of Klebsiella pneumoniae isolated from clinical samples in Iran. Biomed Res. 2016; 27: 1017-26.

12. Martinez-Martinez L, Pascual A, Jacoby GA. Quinolone resistance from a transferable plasmid. Lancet. 1998; 351: 797-9.

13. Jacoby GA, Strahilevitz J, Hooper DC. Plasmid-mediated quinolone resistance. Microbiol Spectr. 2014; 2: 0006-2013. doi: 10.1128/ microbiolspec.PLAS-0006-2013.

14. Yang HY, Nam YS, Lee HJ. Prevalence of plasmid-mediated quinolone resistance genes among ciprofloxacin-nonsusceptible Escherichia coli and Klebsiella pneumoniae isolated from blood cultures in Korea. Can J Infect Dis Med Microbiol. 2014; 225:163-9.

15. Cooke NM, Smith SG, Kelleher M, Rogers TR. Major differences exist in frequencies of virulence factors and multidrug resistance between community and nosocomial Escherichia coli bloodstream isolates. J Clin Microbiol. 2010; 48: 1099-104.

16. Kheiri R, Ranjbar R, Khamesipour F, Akhtari L. Role of antibiotic in drug resistance and integrons prevalence in Escherichia coli isolated from human and animal specimens. Kafkas Univ Vet Fak Derg. 2016; 22: 953-9.

17. Hemmatinezhad B, Khamesipour F, Mohammadi M, Safarpoor Dehkordi F, Mashak Z. Characterization of Escherichia coli in poultry meat. J Food Saf. 2015; 35: 491-500.

18. Pena A, Chmielova D, Lino CM, Solich P. Determination of fluoroquinolone antibiotics in surface waters from Mondego River by high performance liquid chromatography using a monolithic column. J Sep Sci. 2007; 30: 2924-8.

19. Talebiyan R, Kheradmand M, Khamesipour F, Rabiee-Faradonbeh M. Multiple antimicrobial resistance of Escherichia coli Isolated from chickens in Iran. Vet Med Int. 2014; 2014: 491418. doi: 10.1155/2014/491418.

20. Mendonca N, Ramalho J, Vieira P, Da Silva GJ. Association of plasmid-mediated quinolone resistance and virulence markers in Escherichia coli isolated from water. J Water Health. 2012; 10: 28894.

21. Ranjbar R, Pezeshknejad P, Khamesipour F, Amini K, Kheiri R. Genomic fingerprints of Escherichia coli strains isolated from surface water in Alborz province, Iran. BMC Res Notes, 2017; 10, 295. doi: 10.1186/s13104-017-2575-z.

22. Tajbakhsh E, Tajbakhsh S, Khamesipour F. Isolation and molecular detection of gram negative bacteria causing urinary tract infection in patients referred to Shahrekord Hospitals, Iran. Iran Red Crescent Med J. 2015; 17: e24779. doi: 10.5812/ ircmj.17(5)2015.24779.

23. Clinical and Laboratory Standards Institute. Performance Standards for Antimicrobial Susceptibility Testing; Twenty-Second Informational Supplement. CLSI document M100-S22. Wayne, PA: Clinical and Laboratory Standards Institute; 2012.

24. Robicsek A, Sahm F, Strahilvitz J, Jacoby JA. Broader distribution of plasmid-mediated quinolone resistance in United States. Antimicrob Agents Chemother. 2005; 49; 3001-3.

25. Bouchakour M, Zerouali KH, Claude JD, Amarouch H, Mdaghri NE, Courvalian P, et al. Plasmid-mediated quinolone resistance in expanded spectrum beta lactamase producing entrobacteriaceae in Morocco. J Infect Dev Ctries. 2010; 4: 799-803.

26. World Health Organization. Guidelines for drinking-water quality. , Geneva: World Health Organization; 2004.

27. Rahimi E, Khamesipour F, Yazdi F, Momtaz H. Isolation and characterization of enterohaemorragic Escherichia coli O157: H7 and EHEC O157: NM from raw bovine, camel, water buffalo, caprine and ovine milk in Iran. Kafkas Univ Vet Fak Derg. 2012; 18: $559-64$

28. Kariuki S, Revathi G, Corkill J, Kiiru J, Mwituria J, Mirza N, et al. Escherichia coli from community-acquired urinary tract infections resistant to fluoroquinolones and extended-spectrum betalactamase. J Infect Dev Ctries. 2007; 1: 257-62.

29. Yamane K, Wachino J, Suzuki S, Arakawa Y. Plasmid-mediated qepA gene among Escherichia coli clinical isolates from Japan. Antimicrob Agents Chemother. 2008; 52: 1564-6.

30. Pommier Y, Leo E, Zhang H, Marchand C. DNA topoisomerases and their poisoning by anticancer and antibacterial drugs. Chem Biol. 2010; 17: 421-433.

31. Karlowsky JA, Hoban DJ, de Corby MR, Laing NM, Zhanel GG. Fluoroquinolone-resistant urinary isolates of Escherichia coli from out patients are frequently multidrug-resistant: results from the North American urinary tract infection collaborative alliancequinolone resistance study. Antimicrob Agents Chemother. 2006; 50: 2251-4.

32. Ozgumus OB, Celik-Sevim E, Alpay-Karaoglu S, Sandalli C, Sevim A. Molecular characterization of antibiotic resistant Escherichia 
coli strains isolated from tap and spring waters in a coastal region in Turkey. J Microbiol. 2007; 379-387.

33. Constance N, Wose K, Njie A, Tonderai K. Antibiotic resistance profiles of Escherichia coli isolated from different water sources in the Mmabatho locality, North-West Province, South Africa. S Afr J Sci. 2002; 22: 123-62.

34. Divya S, Srinivasan D, Mohamed H. Antibiotic resistance of Escherichia coli serotypes from cochin estuary. Interdiscip Perspect Infect Dis. 2012; 2012; 124879. doi: 10.1155/2012/124879.

35. Coleman BL, Salvadori MI, McGeer AJ, Sibley KA, Neumann NF, Bondy SJ, et al. The role of drinking water in the transmission of antimicrobial-resistant E. coli. Epidemiol Infect. 2012; 140: $633-42$.

36. Pathak SP, Gopal K. Prevalence of bacterial contamination with antibiotic-resistant and enterotoxigenic fecal coliforms in treated drinking water. J T oxicol Environ Health A. 2008; 71: 427-33.

37. Talukdar PK, Rahman M, Rahman M, Nabi A, Islam Z, Hoque $\mathrm{MM}$, et al. Antimicrobial resistance, virulence factors and genetic diversity of Escherichia coli isolates from household water supply in dhaka, Bangladesh. Characterization of E. coli Isolated from Water. PLoS One. 2013; 8: e61090. doi: 10.1371/journal. pone.0061090.

38. Mokracka J, Koczura R, Jabłońska L, Kaznowski A. Phylogenetic groups, virulence genes and quinolone resistance of integronbearing Escherichia coli strains isolated from a waste water treatment plant. Antonie van Leeuwenhoek, 2011; 99: 817-24.

39. Su HC, Ying GG, Tao R, Zhang RQ, Zhao JL, Liu YS. Class 1 and 2 integrons, sul resistance genes and antibiotic resistance in Escherichia coli isolated from Dongjiang River, South China. Environ Pollut. 2012; 169: 42-9.

40. Roe MT, Vega E, Pillai SD. Antimicrobial resistance markers of class 1 and class 2 integron-bearing Escherichia coli from irrigation water and sediments. Emerg Infect Dis. 2003; 9: 822-6.

41. Dhanji H, Murphy N, Akhigbe C, Doumith M, Hope R, Livermore $\mathrm{DM}$, et al. Isolation of fluoroquinolone-resistant O25b:H4-ST131 Escherichia coli with CTX-M-14 extended-spectrum b-lactamase from UK river water. J Antimicrob Chemother. 2011; 66: 512-6.

42. Sun J, Hu J, Peng H, Shi J, Dong Z. Molecular and physiological characterization of fluoroquinolone resistance in relation to uropathogenicity among Escherichia coli isolated from Wenyu River, China. Chemosphere. 2012; 87: 37-42. 